\title{
Factors Influencing Success Rate of Intracytoplasmic Sperm Injection with Azoospermic Male Patients
}

\author{
Faktoren, die die Erfolgsrate der intrazytoplasmatischen \\ Spermieninjektion bei Männern mit Azoospermie beeinflussen
}

(c) (1) $\ominus$

\author{
Authors \\ Ariane Germeyer ${ }^{1}$ \\ Affiliations \\ 1 University Women's Hospital Heidelberg, Department \\ of Gynecological Endocrinology and Fertility Disorders, \\ Heidelberg, Germany \\ 2 University Hospital, Institute of Medical Biometry and \\ Informatics, Heidelberg, Germany \\ 3 Department of Obstetrics and Gynecology, Medicine \\ School, Universidade Federal do Rio Grande do Sul, \\ Porto Alegre, Brazil
}

Julia Rehnitz ${ }^{1}$, Sabine Rösner ${ }^{1}$, Juliane Harsch ${ }^{1}$, Jens Dietrich ${ }^{1}$, Thomas Bruckner ${ }^{2}$, Edison Capp ${ }^{1,3}$, Thomas Strowitzki ${ }^{1}$,

\section{Key words}

testicular sperm extraction, azoospermia, prognostic factors, male infertility

\section{Schlüsselwörter Faktoren, männliche Infertilität

$$
\begin{array}{ll}
\text { received } & 10.12 .2019 \\
\text { revised } & 8.5 .2020 \\
\text { accepted } & 18.5 .2020
\end{array}
$$

testikuläre Spermienextraktion, Azoospermie, prognostische

\section{Bibliography}

DOI https://doi.org/10.1055/a-1180-9094

Geburtsh Frauenheilk 2020; 80: 713-722 @ Georg Thieme Verlag KG Stuttgart · New York I ISSN 0016-5751

\section{Correspondence}

\section{Dr. Julia Rehnitz}

Department of Gynecological Endocrinology and Reproductive Medicine, University Hospital Heidelberg Im Neuenheimer Feld 440, 69120 Heidelberg, Germany julia.rehnitz@med.uni-heidelberg.de

Supporting Information:

https://doi.org/10.1055/a-1180-9094

\begin{abstract}
Introduction Azoospermia affects about 1\% of men, of whom up to $15 \%$ inquire about infertility treatment. Information about predictive factors for these couples is very limited. Patients, Materials and Methods We performed a retrospective analysis of the clinical records of 118 cycles of intracytoplasmic sperm injection treatment after testicular sperm extraction for male azoospermia carried out between January 2008 and October 2015. Of those, 66 were first, 35 second, and 17 third cycles. Statistical significance was set at $p<0.05$. Predictive factors for successful pregnancy were evaluated and included male/female age, male/female body mass index, male/female nicotine use, and histological results of testes biopsies.

Results Embryo quality and the number of embryos transferred were positively associated with pregnancy success $(p=0.003)$. Males whose partners conceived had a significantly lower body mass index than those whose partners did not conceive $(p=0.023)$. Neither female weight nor age nor smoking status of the male or female were significant factors. In cases with tubular atrophy $\geq$ SIGG grade 4 the chance of pregnancy was poor, irrespective of the existence of mature sperm and the number of cycles performed.

Conclusion Overweight male patients should be advised about weight reduction prior to treatment, and counseling about success rates should include histological and spermpositive biopsy results.
\end{abstract}

\section{ZUSAMMENFASSUNG}

Einleitung Etwa 1\% aller Männer sind von Azoospermie betroffen; davon suchen bis zu 15\% Rat bezüglich einer Infertilitätsbehandlung. Informationen über prädiktive Faktoren für betroffene Paare sind hierbei sehr begrenzt.

Patienten, Materialien und Methoden Wir führten eine retrospektive Analyse medizinischer Aufzeichnungen von 118 Zyklen intrazytoplasmatischer Spermieninjektionen nach vorheriger testikulärer Spermienextraktion wegen Azoospermie durch. Die Behandlungen wurden zwischen Januar 2008 und Oktober 2015 vorgenommen. Von 188 Zyklen waren 66 
erste Behandlungszyklen; 35 waren zweite Behandlungszyklen, und 17 waren dritte Behandlungszyklen. Eine statistische Signifikanz wurde bei $p<0,05$ angenommen. Es wurden prädiktive Faktoren für eine erfolgreiche Schwangerschaft ausgewertet; dazu gehörten männliches/weibliches Alter, männlicher/weiblicher Body-Mass-Index, männlicher/weiblicher Tabakkonsum und histologische Ergebnisse von testikulären Biopsien.

Ergebnisse Die Embryonenqualität und die Anzahl der transferrierten Embryonen waren positiv mit einer erfolgreichen Schwangerschaft assoziiert $(p=0,003)$. Männer, deren Partnerinnen schwanger wurden, hatten einen signifikant nied- rigeren Body-Mass-Index verglichen mit Männern, deren Partnerinnen nicht schwanger wurden $(p=0,023)$. Weder weibliches Gewicht noch Alter noch Tabakkonsum beim Mann oder bei der Frau waren signifikante Faktoren. Bei Männern mit einer tubulären Atrophie $\geq$ SIGG Grad 4 war die Wahrscheinlichkeit einer Schwangerschaft gering, ungeachtet dem Vorfinden reifer Spermien und der Anzahl durchgeführter Zyklen. Schlussfolgerung Übergewichtigen Patienten sollte zu einer Gewichtsreduktion vor Beginn der Behandlung geraten werden, und die Beratung samt Erfolgsraten sollte Informationen über histologische und positive Biopsieergebnisse enthalten.

\section{Introduction}

Azoospermia is defined as a total absence of spermatozoa in ejaculated semen. The condition affects $1 \%$ of the male population and $10-15 \%$ of patients undergoing evaluation for infertility [1]. Azoospermia is divided into non-obstructive azoospermia (no spermatozoa production) and obstructive azoospermia (the absence or obstruction of ejaculatory ducts) [2]. Since the development of testicular sperm extraction (TESE), men with azoospermia have a chance to father their own children by combining the procedure with intracytoplasmic sperm injection (ICSI) [3]. Therefore, the aim of this study was to identify predictive clinical and biological factors that contribute to the success rate of ICSI-TESE treatment and help to better estimate individual chances of achieving pregnancy in couples with azoospermic men.

In subfertile men, chromosomal aberrations, such as Klinefelter Syndrome, and genetic problems, such as cystic fibrosis transmembrane conductance regulator (CFTR) mutations and azoospermia factor (AZF) deletions, are more prevalent compared with fertile men [4-8].

The most common pathological finding in cases of non-obstructive azoospermia is tubular atrophy, which leads to the impairment or arrest of spermatogenesis. The degree of atrophy and impairment of spermatogenesis can be categorized using the scale proposed by Sigg, which ranges from slight atrophy with hypospermatogenesis (SIGG 1) to complete fibrosis and lack of spermatogenesis (SIGG 5) [9]. Due to the presence of variegated atrophy, the degree of atrophy can differ depending on the cross section that is assessed [10].

In vitro fertilization (IVF) is a well-established treatment for a lot of cases of infertility. However, in cases with extremely low sperm counts, impaired motility, and poor morphology, fertilization can only be achieved by ICSI, which has been used for more than 20 years [11]. In men with azoospermia, spermatozoa can be retrieved from testicular tissue samples; however, reported retrieval rates differ, ranging from 41 to $86.6 \%[12,13]$. This may be due to differences in patient selection resulting in an overestimation of retrieval rates $[3,14]$. Furthermore, reported ICSI outcomes vary widely, mainly due to selection bias $[3,15]$. There is little data available on pregnancy rates after TESE/ICSI [17].

Embryos are chosen for uterine transfer according to the timing and rate of cell division and morphology. Factors considered in the grading of embryo quality (day 2-3) include cell number, degree of fragmentation, cell symmetry, and the presence/absence of cytoplasmic pitting [19]. In addition, blastocyst classification (on day 4-5) includes stage of development, inner cell mass, and trophectoderm cells [19]. Implantation and live-birth rates have been reported to be associated with the morphology of embryos and blastocysts [19-21].

Clinical parameters such as weight and smoking status are associated with an impact on the outcomes following assisted reproductive techniques. For example, obesity and smoking negatively influence male fertility by impairing semen parameters [22-24].

\section{Patients, Material and Methods}

\section{Study aim and design}

Little is known about the clinical factors that affect the success of ICSI among couples undergoing treatment following sperm-positive testicular biopsy. This retrospective study aimed to assess the significance of various clinical and biological parameters relevant to the outcomes of TESE/ICSI treatment. The primary outcome parameter was the pregnancy rate; the secondary outcomes were the effects of age, BMI, smoking, histological results, fertilization rate and rate of embryo transfers on the pregnancy rate.

\section{Participants}

We recruited and included all couples who gave their consent after attending the Department of Gynecological Endocrinology and Fertility Disorders, University Women's Hospital Heidelberg, Germany, for TESE/ICSI treatment from January 2008 through October 2015. Exclusion criterion was the complete absence of sperm after testicular biopsy, which prevented TESE/ICSI treatment and could therefore not lead to pregnancy.

\section{Data collection}

We collected data on age, body mass index (BMI), nicotine consumption of both partners at the time of first consultation, testicular pathology after TESE procedure, fertilized oocytes, transferred embryos, embryo quality, and pregnancy rates by reviewing the medical records. Pregnancy was defined as a positive pregnancy test two weeks after oocyte pickup and assessed by serum 
hCG 14 days after oocyte pickup (HCG $>10 \mathrm{mlU} / \mathrm{ml}=$ positive). Abortion was included in the evaluation if it occurred within the first 6 to 9 weeks of gestation. Pregnancies were followed up by ultrasound imaging during the period starting two weeks after the positive pregnancy test, and patients were then referred to a specialist for further prenatal care after detection of a positive heartbeat (ongoing pregnancy rate). Further follow-up was not covered by this study. The cumulative pregnancy rate was calculated based on the first 4 fresh cycles with embryo transfer that were performed per couple (including all commenced treatment cycles) and all positive pregnancy tests were included in the evaluation. Only two couples underwent 5 or more fresh cycles.

According to the patient management protocol, azoospermia was diagnosed based on evidence from two spermiograms.

\section{Testicular sperm extraction}

Couples were advised to seek genetic counseling prior to TESE, during which they were informed about the option of TESE/ICSI treatment.

The procedure was performed in the Urological University Hospital, Heidelberg under general anesthesia. Testicular tissue was removed using the "no-touch technique" to avoid mechanical damage to tissue and artifacts for the histological examination [25]. Five biopsies were taken from each testis, and one sample from each side was used for histological examination at the Pathology Institute of the University Hospital, Heidelberg. All other testicular biopsies were taken to the IVF Laboratory of the University Women's Hospital, Heidelberg. The presence of sperm in tissue was evaluated by microscopy (Nikon Ti-S inverse microscope at 200-400-fold magnification) in a small piece from each sample, which was enzymatically digested by incubation with $600 \mathrm{IU}$ collagenase (Collagenase Type IA, Sigma, C2674) at $37^{\circ} \mathrm{C}$ for $1-$ 3 hours.

\section{Cryopreservation of testicular tissue}

Testicular biopsies were cryopreserved using the Biological Freezing System Type BV-65 (Consarctic GmbH, Schöllkrippen, Germany). Before freezing, cryoprotective medium (Sperm Freeze ${ }^{\circledR}$, Ferti Pro, Berlin, Germany) was added to the samples. After stepwise freezing down to $-196^{\circ} \mathrm{C}$, biopsies were stored in liquid nitrogen.

Before ICSI, a cryopreserved sample was thawed in a water bath at $37^{\circ} \mathrm{C}$ for approx. 3 minutes. The testicular tissue was briefly washed in sperm preparation medium (SPM, Origio, $10700060 \mathrm{~A}$ ), enzymatically dissociated with $600 \mathrm{IU}$ collagenase (Collagenase Type IA, Sigma, C2674) at $37^{\circ} \mathrm{C}$ for $1-4$ hours or overnight and washed twice in SPM.

\section{Intracytoplasmic sperm injection}

When sperms were identified in the testicular biopsy, the female partner underwent stimulation for ICSI. Ovarian stimulation was performed as previously described [26]. The appropriate protocol and the cumulative dose of gonadotropins were determined based on patients' responses and the decisions made by the treating physicians. Women were treated with one of the following:
1. the long-stimulation protocol, involving downregulation by administration of a GnRH analogue (Synarela ${ }^{\circledR}$, Pharmacia $\mathrm{GmbH}$, Pfizer) followed by recombinant follicle-stimulating hormone (Gonal ${ }^{\circledR}$, Merck Pharma GmbH, Darmstadt, Germany) or urinary hMG preparation (Menogon ${ }^{\circledR}$, Ferring $\mathrm{GmbH}$, Kiel, Germany); or

2. the short protocol, in which downregulation was induced with a GnRH analogue from day 2 of the cycle; or

3. the antagonist protocol, starting with stimulation with gonadotropins on day 2 or 3, and administration of a GnRH antagonist from day 5 to 7 (Orgalutran ${ }^{\circledR}$, MSD Merck, Sharp \& Dohme Corp. or Cetrotide ${ }^{\circledR}$, Merck Germany) [26].

As soon as at least three follicles reached a diameter of 1718 mm, ovulation was triggered (Ovitrelle ${ }^{\circledR}$, Merck Pharma GmbH or Predalon ${ }^{\circledR}$, MSD Sharp \& Dohme $\mathrm{GmbH}$ ). This was followed 3638 hours later by transvaginal ultrasound-guided follicular puncture under general anesthesia. ICSI was performed on mature oocytes in Sydney IVF Gamete Buffer (K-SIGB-50; Cook Medical) with the sperm retrieved from thawed testicular samples. The fertilization rate was evaluated after $16-18$ hours, as described previously [3]. Oocytes and embryos were cultured in vitro using sequential media with media changed on day 3. The concentration of $\mathrm{CO}_{2}$ was set to adjust the $\mathrm{pH}$ of the culture medium within a range of 7.25-7.35. Culture until day 3 was performed in Sydney IVF Cleavage Medium (K-SICM-20; Cook Medical) covered with paraffin oil (10100060A; Origio). In the case of extended culture until day 5, a change of media was performed on day 3 of culture by replacing the spent medium with preequilibrated Sydney IVF Blastocyst Medium (K-SIBM-20; Cook Medical). Cleavage stage embryos were scored based on a modified grading scheme by Veek [27], which scored cell numbers, degree of fragmentation, and symmetry of cells. Grade A included embryos with equally sized blastomeres and no fragmentation, grade $B$ included embryos with equally sized blastomeres and $<10 \%$ fragmentation, grade $C$ included embryos with unequally sized blastomeres and/or fragmentation of $10-50 \%$, whereas grade D included embryos with $>50 \%$ fragmentation. The grading scheme for cleavage stage embryos was adjusted during the study period. The term "equally sized" was replaced with "stage-specific". The scoring of fragmentation was adjusted to grade $A<10 \%$, grade B $10-25 \%$, grade C $>25-50 \%$ and grade $D>50 \%$. On day 4 the initiation of compaction and morula formation were assessed. Blastocysts were scored based on the grading scheme by Gardner et al. [28]. Briefly, the degree of blastocyst cavity expansion was assessed, with grade 1 achieving $<50 \%$, grade 2 achieving $>50 \%$ and grade 3 reaching up to $100 \%$ of the embryo volume. Grade 4 included a cavity expansion of $100 \%$ embryo volume and thinning of the zona pellucida of more than 50\%. Grade 5 included hatching and grade 6 consisted of fully hatched blastocysts. In addition, the quality of the inner cell mass (ICM) and trophectoderm (TE) were assessed. The ICM of grade A consisted of many tightly packed cells. Grade B consisted of several loosely grouped cells, and grade $C$ consisted of very few cells. The TE of grade A consisted of many cells forming a cohesive epithelium, grade B consisted of a few cells forming a loose epithelium, and grade $\mathrm{C}$ consisted of very few large cells. 
- Table 1 Demographics: mean numbers of oocytes, fertilization rate, embryos per couple, abortion and pregnancy rates are detailed in $>$ Table 1.

\begin{tabular}{|l|c|c|c|}
\hline & Cycle $\mathbf{1}(\mathbf{9 0}$ couples) & Cycle $\mathbf{2}$ (42 couples) & Cycle 3 (19 couples) \\
\hline Couples with follicles (n) & $87 / 90(96.7 \%)$ & $42 / 42(100.0 \%)$ & $18 / 19(94.7 \%)$ \\
\hline Number of follicles per puncture (mean \pm SD; min-max) & $9.9 \pm 8.0(0-42)$ & $10.8 \pm 7.28(2-32)$ & $10.4 \pm 7.4(0-28)$ \\
\hline Couples with MII cells & $86 / 90(95.6 \%)$ & $42 / 42(100.0 \%)$ & $18 / 19(94.7 \%)$ \\
\hline Number of MIl cells (mean \pm SD; min-max) & $7.5 \pm 6.10(0-40)$ & $8.71 \pm 5.78(1-23)$ & $7.8 \pm 5.07(2-21)$ \\
\hline Couples with fertilization & $71 / 86(82.6 \%)$ & $35 / 42(83.3 \%)$ & $17 / 18(94.4 \%)$ \\
\hline Fertilization rate (mean \pm SD; min-max) & $38.1 \pm 29.8(0-100)$ & $32.5 \pm 23.92(0-88)$ & $45.1 \pm 30.0(0-100)$ \\
\hline Number of cells with 2PN (mean \pm SD; min-max) & $2.9 \pm 3.7(0-21)$ & $3.0 \pm 2.9(0-11)$ & $3.5 \pm 3.1(0-11)$ \\
\hline Couples with embryo transfer & $66 / 90(73.3 \%)$ & $35 / 42(83.3 \%)$ & $17 / 19(89.5 \%)$ \\
\hline Number of cells transferred (mean \pm SD; min-max) & $1.6 \pm 0.5(1-3)$ & $1.6 \pm 0.5(1-2)$ & $1.8 \pm 0.4(1-2)$ \\
\hline Pregnancy rate/embryo transfer & $21 / 66(31.8 \%)$ & $13 / 35(37.1 \%)$ & $2 / 17(11.8 \%)$ \\
\hline Pregnancy rate/couple & $21 / 90(23.3 \%)$ & $13 / 42(31 \%)$ & $2 / 19(10.5 \%)$ \\
\hline Abortion/pregnancy (\%) & $4 / 21(19.0 \%)$ & $2 / 13(15.4 \%)$ & $0 / 2(0 \%)$ \\
\hline Ongoing pregnancy rate/ET (\%) & $17 / 66(25.8 \%)$ & $11 / 35(31.4 \%)$ & $2 / 17(11.8 \%)$ \\
\hline Ongoing pregnancy rate/couple & $17 / 90(18.9 \%)$ & $11 / 42(26.2 \%)$ & $2 / 19(10.5 \%)$ \\
\hline ET = embryo transfer & & & \\
\hline
\end{tabular}

High-quality embryos were defined as those with six to eight cells on day 3 , or three or four cells on day 2 respectively, classed as degree $A$ and $B$. Poor-quality embryos included those with fewer cells and/or classed as degree C or D. Classification of blastocysts was carried out according to the developmental stage, formation of the inner cell mass, and cell integrity of the trophectoderm [19]. Accordingly, they were defined as good quality embryos if they met the following classifications $\geq 3 A A, 1-2 A A$, $3-6 A B$ and 3-6BA. Embryos classified as 1-6BC, 1-6CB, 1-6CC or 1-2BB were considered low quality embryos.

\section{Statistical analysis}

Continuous data are presented as mean \pm standard deviation (SD) or minimum and maximum, categorical data as absolute and relative frequencies ( $n$, \%). Associations were determined using crosstabs and chi-squared tests, and the significance level was set at $p<0.05$. Statistical analyses were carried out using SAS/ $\mathrm{STAT}^{\circledR}$ (SAS Institute, Inc., Cary, NC, USA).

\section{Results}

\section{Demographics}

We recruited 105 couples; of these, 15 were excluded due to no sperm in the biopsy. Finally, 90 couples were enrolled and underwent a total of 168 ICSI cycles. A first cycle was performed in all 90 couples, and oocytes were obtained from 87 (96.7\%). For 86 couples (95.6\%), oocytes reached maturation (MIl oocytes). Of these, MII-oocyte fertilization with evidence of two pronuclei was achieved in 71 couples (82.6\%). Embryo transfer was carried out in 66 couples (73.3\%). In the remaining 5 couples, embryos had to be cryopreserved due to ovarian hyperstimulation syndrome or cervical stenosis. The 66 transfers resulted in 21 preg- nancies (pregnancy rate per transfer $=31.8 \%$ ) ( $>$ Table 1 ). A second cycle was performed in 42 couples. Oocytes were obtained from all 42, and fertilization and embryo transfer were achieved in 35 couples (83.3\%). Thirteen pregnancies occurred after embryo transfer in these 35 couples (pregnancy rate per transfer $=37.1 \%$ ) ( $\triangleright$ Table 1 ). A third cycle was performed in 19 couples. Oocytes were obtained from 18 couples (94.7\%); fertilization was achieved and embryo transfer was possible in 17 couples (94.4\%). Two pregnancies resulted among the 17 couples (pregnancy rate per transfer $=11.8 \%$ ) ( $\vee$ Table 1$)$. A fourth cycle was performed in nine couples. Oocytes could be obtained in all cases, fertilization was achieved in six couples (66.7\%), and embryo transfer was possible in five (55.6\%). This resulted in one pregnancy (pregnancy rate per transfer $=20 \%$ ). These results are summarized in the flow chart in $>$ Fig. 1. Two couples underwent more than five cycles (16 cycles in total). Embryo transfer was possible in 13 of the 16 cycles (81.3\%), resulting in three pregnancies (cumulative pregnancy rate per transfer $=18.8 \%$ ). The mean numbers of oocytes, fertilization rate and embryos per couple of the first three cycles are detailed in $>$ Table $\mathbf{1}$.

The cumulative rate of a positive pregnancy test per embryo transfer for the first 4 fresh cycles in our study population was $56 \%$ (37/66); per couple we had a cumulative rate of positive pregnancy tests of $41 \%(37 / 90)$ in the first 4 cycles. The latter includes all couples who started the treatment, including the ones without embryo transfer. For the ongoing pregnancy rates, we found a cumulative pregnancy rate for the first 4 fresh cycles of $47 \%(31 / 66)$ per cycles with embryo transfer or $34.4 \%(31 / 90)$ per couple, respectively.

For all included couples during all cycles, supernumerary embryos were cryopreserved for later embryo transfers. Results of transfers after the cryopreservation of embryos were not assessed. 


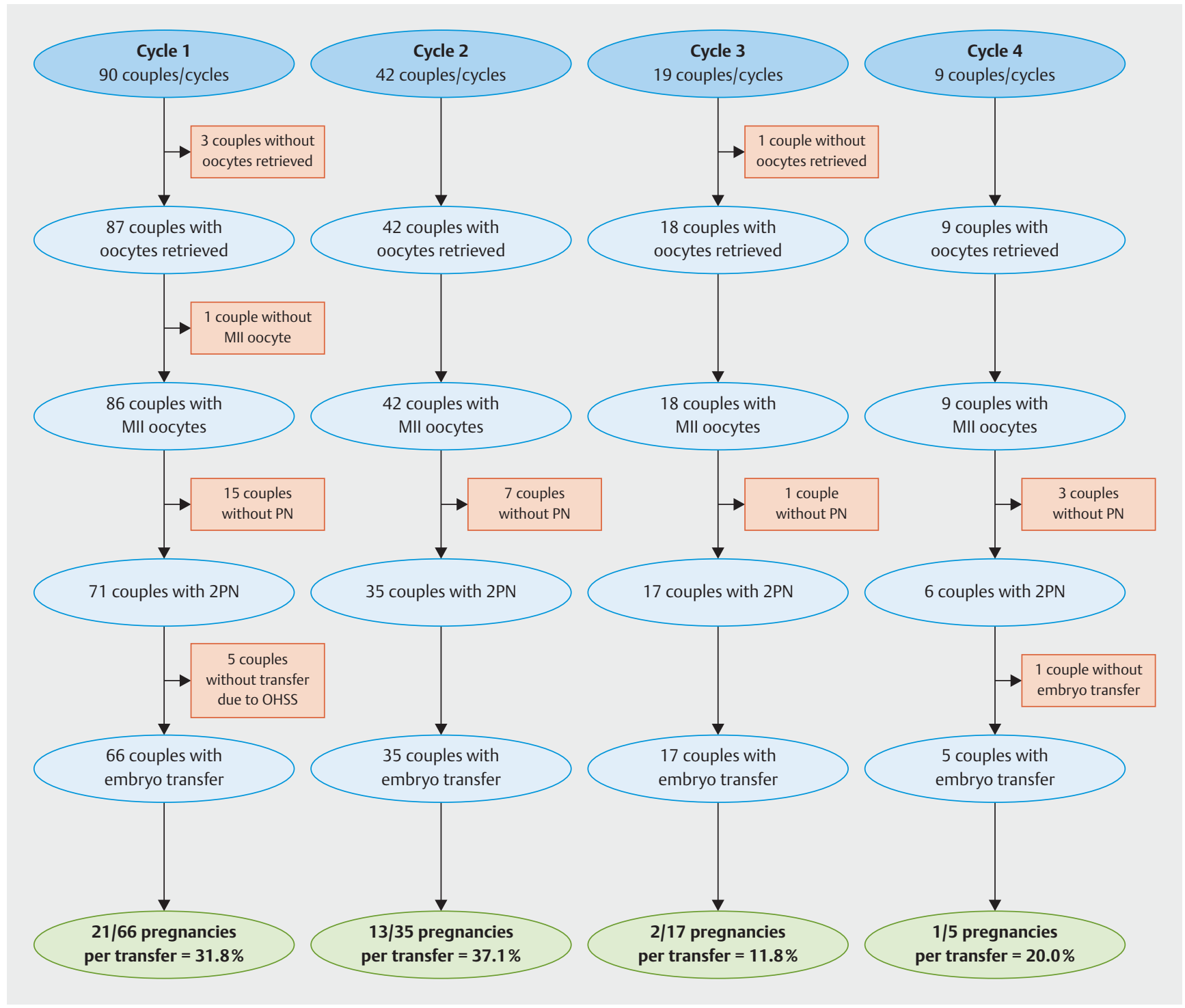

- Fig. 1 Flow chart diagram summarizing the results of the first four cycles of evaluated couples.

\section{Age, BMI and pregnancy rate}

In the first cycle, pregnancy rates were higher when the male partner had a lower BMI $(p=0.023)$, and for men who smoked $(58.3 \%)$ compared with non-smokers $(27.9 \%, p=0.05)(\triangleright$ Table 2). It should be noted that among non-smokers, more patients suffered from higher-grade SIGG testicular atrophy than smokers (Tables S1 and S2). Pregnancy rates showed no statistically significant relationship with BMI or smoking status for the second or third cycles. The mean ages of both men and women were not significantly related to treatment outcome ( $\bullet$ Table 2 ).

\section{Pathological findings, smoking and pregnancy rate}

Patients who had planned to undergo TESE/ICSI but in whom no sperm was detected were not recorded in the IVF laboratory of the University Women's Hospital Heidelberg until 2010. Therefore, only 15 patients with negative sperm specimens were recorded between 2010 and 2015. Of these, 26.7\% were classified as SIGG grade 2, 20.0\% as grade 3, 26. $7 \%$ as grade 4 and $26.7 \%$ as grade 5 , which was higher than men who had sperm-positive biopsies (Table S2 details SIGG grades of men with sperm-positive biopsies). In all cycles, the highest rates of fertilization and pregnancy were achieved in men who did not exhibit pathological findings ( $~$ Table 3 ). Fertilization could not be achieved for 15 couples. The histological findings of the men in these couples were as follows: No pathology was available for two (13.3\%); no atrophy was observed in five $(33.3 \%)$; and two $(13.3 \%)$, three $(20.0 \%)$, two (13.3\%), and one (6. $7 \%$ ) were classified as SIGG grade 1, 2, 3 , and 4 , respectively.

\section{Embryo quality and pregnancy rate}

The majority of embryos transferred were day 2 or 3 embryos. Table S3 lists the distribution of transferred embryos in terms of quality and time point of transfer. Pregnancy rate following transfer was significantly affected by the number and quality of the 
- Table 2 Age and BMI. Pregnancy rate depending on age and BMI of both partners during the first three cycles.

\begin{tabular}{|c|c|c|c|c|}
\hline & Pregnancy & Cycle 1 & Cycle 2 & Cycle 3 \\
\hline \multirow{2}{*}{$\begin{array}{l}\text { BMI man }\left(\mathrm{kg} / \mathrm{m}^{2}\right) \\
\text { [range 19-34] }\end{array}$} & Yes & $25.5 \pm 2.8(n=19)$ & $26.9 \pm 4.7(n=11)$ & $32.1 \pm 7.4(n=2)$ \\
\hline & No & $28.7 \pm 5.9(n=35)^{*}$ & $27.6 \pm 3.3(n=18)$ & $26.7 \pm 2.9(n=12)$ \\
\hline \multirow{2}{*}{$\begin{array}{l}\text { Age of man (years) at TESE } \\
\text { (mean } \pm \text { SD) [range } 28-73 \text { yrs.] }\end{array}$} & Yes & $37.1 \pm 7.3(n=21)$ & $38.3 \pm 6.1(n=13)$ & $36.2 \pm 0.2(n=2)$ \\
\hline & No & $38.8 \pm 5.8(n=43)$ & $38.8 \pm 5.5(n=22)$ & $38.7 \pm 4.4(n=15)$ \\
\hline \multirow{2}{*}{$\begin{array}{l}\text { BMI woman }\left(\mathrm{kg} / \mathrm{m}^{2}\right) \\
\text { [range 17-44] }\end{array}$} & Yes & $24.7 \pm 7.0(n=21)$ & $23.7 \pm 7.5(n=13)$ & $25.5 \pm 8.7(n=2)$ \\
\hline & No & $24.3 \pm 4.1(n=43)$ & $24.3 \pm 4.2(n=22)$ & $25.2 \pm 3.7(n=15)$ \\
\hline \multirow{2}{*}{$\begin{array}{l}\text { Age of woman (years) at TESE } \\
\text { (mean } \pm \text { SD) [range } 23-44 \text { yrs.] }\end{array}$} & Yes & $33.1 \pm 4.4(n=21)$ & $34.0 \pm 4.6(n=13)$ & $38.5 \pm 2.2(n=2)$ \\
\hline & No & $34.4 \pm 4.9(n=45)$ & $35.6 \pm 3.7(n=22)$ & $36.0 \pm 3.7(n=15)$ \\
\hline
\end{tabular}

- Table 3 Pathological findings and pregnancy. Results of histopathological analysis, fertilization and pregnancy rates for the first three cycles.

\begin{tabular}{|l|l|l|l|l|l|l|}
\hline & \multicolumn{2}{|l|}{ Cycle 1 } & Cycle 2 & \multicolumn{2}{l|}{ Cycle 3 } \\
\hline & $\begin{array}{l}\text { Fertilization } \\
(\% \pm \text { SD, min-max) }\end{array}$ & $\begin{array}{l}\text { Pregnancy } \\
\text { rate* }\end{array}$ & $\begin{array}{l}\text { Fertilization } \\
(\% \pm \text { SD, min-max) }\end{array}$ & $\begin{array}{l}\text { Pregnancy } \\
\text { rate* }\end{array}$ & $\begin{array}{l}\text { Fertilization } \\
(\% \pm \text { SD, min-max) }\end{array}$ \\
\hline $\begin{array}{l}\text { No pathological } \\
\text { examination }\end{array}$ & $43.9 \pm 31.9(0-100)$ & $3 / 12(25 \%)$ & $45.4 \pm 19.2(25-75)$ & $1 / 5(20.0 \%)$ & $33.0 \pm 0$ \\
\hline No atrophy & $43.1 \pm 29.8(0-100)$ & $9 / 29(31.0 \%)$ & $34.94 \pm 27.7(0-88)$ & $7 / 13(53.9 \%)$ & $58.0 \pm 33.1(0-100)$ & $1 / 6(16.7 \%)$ \\
\hline SIGG 1 & $38.9 \pm 34.6(0-100)$ & $5 / 9(55.6 \%)$ & $34.5 \pm 22.0(20-67)$ & $1 / 4(25.0 \%)$ & - & $0 / 0(0 \%)$ \\
\hline SIGG 2 & $26.8 \pm 26.0(0-75)$ & $2 / 8(25.0 \%)$ & $25.4 \pm 17.4(0-53)$ & $3 / 7(42.9 \%)$ & $38.3 \pm 36.5(13-100)$ & $0 / 4 \%(0 \%)$ \\
\hline SIGG 3 & $23.0 \pm 22.6(0-56)$ & $2 / 5(40.0 \%)$ & $20.6 \pm 27.0(0-64)$ & $1 / 3(33.3 \%)$ & $35.7 \pm 17.6(17-52)$ & $1 / 3(33.3 \%)$ \\
\hline SIGG 4 & $38.3 \pm 30.6(0-75)$ & $0 / 3(0 \%)$ & $33.7 \pm 30.6(7-67)$ & $0 / 3(0 \%)$ & $37.7 \pm 23.4(17-63)$ & $0 / 3(0 \%)$ \\
\hline * Pregnancy rate was calculated per couple with embryo transfer. & & & \\
\hline
\end{tabular}

transferred embryos $(\triangleright$ Table $4 \mathbf{a})$. The highest pregnancy rate was observed after the transfer of two good quality embryos in the first cycle $(p=0.003)$. An analysis of transfers after subdividing into day $2 / 3$ or $4 / 5$ showed no significant differences in pregnancy rates between groups ( $\bullet$ Table $\mathbf{4} \mathbf{b}$ and $\mathbf{c}$ ).

\section{Genetic reasons}

Genetic consultations and examinations were carried out in 90 men. A CTFR mutation was identified in eight men (8.9\%). The couples with men with CFTR mutations underwent between 1 and 10 cycles. Five of the eight couples achieved pregnancies. In six of eight cases, there were no pathological findings, and in two cases only mild pathological findings (SIGG 1, 2) were detected in the biopsies.

\section{Discussion}

This study evaluates the predictive clinical and biological factors that contribute to the chance of pregnancy in couples with azoospermic males undergoing TESE/ICSI treatment. Preexisting clinical factors prior to any TESE/ICSI treatment as well as clinical parameters during that treatment were considered.
The present study reveals that the pregnancy rate after TESE depends significantly on the quality of the embryo. The more qualitatively good embryos that are transferred, the higher the chance of pregnancy. It has previously been demonstrated that the transfer of high-quality embryos increases implantation and pregnancy rates after IVF [29], while the transfer of low-quality embryos results in higher miscarriage and lower ongoing pregnancy rates [30]. Thus, embryo quality appears to be an important prognostic factor for the outcome of ICSI after TESE as well. In the present study, this significant difference was no longer observed when patients were divided into embryo transfer on day $2 /$ 3 and day 4/5; this may be due to the limited number of patients. Additionally, the $p$-value of the pregnancy rate in the first cycle almost reached significance for day $2 / 3$ embryos (0.056); and for blastocyst transfers, only a single transfer with a poor-quality embryo was identified.

Our results indicate that the ongoing pregnancy rate decreases significantly by the third cycle of TESE/ICSI. This clearly shows that the chance of pregnancy decreases over time, possibly due to the fact that patients with a poorer prognosis often require multiple cycles. Our cumulative rate for a positive pregnancy test was $56 \%$, with an ongoing pregnancy rate of $47 \%$ per embryo transfer, and $41 \%$, or $34.4 \%$ respectively for all couples treated after 4 fresh 
- Table 4 Pregnancy rate per transfer and embryo quality.

\begin{tabular}{|c|c|c|c|}
\hline & Cycle 1 & Cycle 2 & Cycle 3 \\
\hline \multicolumn{4}{|c|}{ a All embryos day $2 / 3$ and day 5 cumulative } \\
\hline Embryo quality & $n=66$ & $\mathrm{n}=35$ & $n=17$ \\
\hline . 1 good & $8 / 29(27.6 \%)$ & $6 / 17(35.3 \%)$ & $0 / 7(0 \%)$ \\
\hline . 2 good & $10 / 18(55.6 \%)$ & $5 / 10(50 \%)$ & $2 / 7(28.6 \%)$ \\
\hline - all bad & $1 / 19(15.8 \%)$ & $2 / 8(25 \%)$ & $0 / 3(0 \%)$ \\
\hline$p$-value & $0.003^{*}$ & 0.5384 & 0.289 \\
\hline \multicolumn{4}{|l|}{ b day $2 / 3$ embryos } \\
\hline Embryo quality day $2 / 3$ & $n=57$ & $n=28$ & $n=1715$ \\
\hline $.1 \operatorname{good}$ & $6 / 26(23,1 \%)$ & $4 / 13(30,8 \%)$ & $0 / 6(0 \%)$ \\
\hline - 2 good & $7 / 13(53,9 \%)$ & $4 / 8(50 \%)$ & $1 / 6(16,7 \%)$ \\
\hline - all bad & $3 / 18(16,7 \%)$ & $1 / 7(14,3 \%)$ & $0 / 3(0 \%)$ \\
\hline p-value & 0.056 & 0.332 & 0.448 \\
\hline \multicolumn{4}{|l|}{ c day 5 embryos } \\
\hline Blastocyst quality day $4 / 5$ & $n=9$ & $n=7$ & $n=2$ \\
\hline - 1 good & $2 / 3(66,7 \%)$ & $2 / 4(50 \%)$ & $0 / 0$ \\
\hline . 2 good & $3 / 5(60 \%)$ & $1 / 2(50 \%)$ & $1 / 1(100 \%)$ \\
\hline - all bad & $0 / 1(0 \%)$ & $1 / 1(100 \%)$ & $0 / 0$ \\
\hline p-value & 0.487 & 0.646 & - \\
\hline
\end{tabular}

cycles. These results are in accordance with other studies that found comparable cumulative pregnancy rates after IVF/ICSI treatment [46] and suggest that TESE per se, when sperm are found within the biopsy, does not further negatively affect patient outcomes.

Obesity and overweight status are global public health issues and a major clinical concern [31]. Reduced fertility has been associated with overweight status and obesity in men [32], with overweight men exhibiting lower sperm quality and reduced sperm counts compared with normal-weight men [33,34]. Additionally, the molecular structure, i.e., the miRNA profile in spermatozoa and testicular somatic cells which affects sperm maturation and function, has been described as altered in overweight patients [35]. Weight loss has been suggested to improve semen quality and fertility [36]. We observed a significant association between male BMI and pregnancy rate, which is consistent with previous studies which showed that couples with lower-BMI men had higher pregnancy rates [37]. This is also reflected in the guidelines that advise weight reduction in obese men prior to ART [38]. Higher $\mathrm{BMI}$ may lead to increased temperature in obese men's testes $[39,40]$, and oxidative stress in the testes can lead to DNA fragmentation and mitochondrial dysfunction, which negatively affects sperm quality and motility [41].

The women in our study had in median normal BMIs. Obesity is associated with lower rates of live births after IVF and ICSI, along with impaired responses to ovarian stimulation [2,43]. Furthermore, increased BMI in women may have a negative effect on embryo quality and, therefore, on the outcome of assisted-reproduction treatment [44].
Our study found that male age did not influence fertilization, embryo cleavage, or pregnancy rate, which is consistent with previous research [45]. However, another study reported significant correlations between male age and pregnancy and birth rates [47]. This is likely due to decreases in sperm count, motility, vitality, and morphology that occur with increased age. In our study, female age had no significant impact on the outcome of TESE/ICSI. This may be due to the homogeneous age distribution of our population, since female age is one of the most important factors associated with the success of ICSI [46].

Smoking is a potential risk factor for infertility, and has a negative effect on sperm quality $[48,49]$, particularly sperm density, count, and morphology [50]. Nicotine use by women may adversely affect the outcome of IVF/ICSI treatment, due to decreased endometrial thickness on the day of embryo transfer [51]; reduced rates of fertility, pregnancy, and live birth; and a higher risk of miscarriage [52]. However, we did not find smoking to be associated with worse outcomes, probably because the underlying pathological findings were milder among those who smoked.

In the present study, men were subdivided into groups according to their pathological TESE findings. Although no pathological examinations had been documented for 14 men, mature spermatozoa were found in all of these men. Of the remaining $76 \mathrm{pa}$ tients, mature spermatozoa were found in patients categorized as SIGG grades 1-4. Although finding sperm in patients categorized as SIGG 4 is not expected, a fertilization rate of $38.3 \pm 30.6 \%$ was achieved in those couples where men's biopsies were diagnosed as SIGG 4. This is consistent with a recently published study which showed that $14 \%$ of patients with Sertoli-Cell-Only Syndrome 
(SIGG 4) and sperm-positive TESE were able to proceed to ICSI [50]. In contrast, in $26.6 \%$ of patients categorized as SIGG 2 , sperm could not be found. It has been suggested that once spermatozoa are found, fertilization and pregnancy rates do not differ significantly with regard to SIGG grade [53]. However, this was not the case in the present study. The presence of sperm tubules with spermatozoa in the TESE biopsy is an important predictor of successful sperm retrieval [54]. Classification as SIGG grade 5 was the only pathological finding associated with no detectable sperm in our population. Therefore, our results indicate that the degree of testicular atrophy other than total fibrosis (SIGG 5) is not prognostic for the detection of mature sperm. Nevertheless, no pregnancies were achieved for patients categorized as SIGG grade 4, which could be postulated as a negative predictive factor for therapy success in those couples.

The highest pregnancy rates were observed in the present study when no atrophy or pathology were documented, as is the case after vasectomy, or when only slight atrophy (SIGG 1) was described. Regardless of the detection of mature sperm, a diagnosis of SIGG grade 4 was associated with no pregnancy. To summarize, higher testicular atrophy is associated with lower pregnancy success rates after TESE/ICSI.

\section{Strengths and limitations}

Our study found that smoking had no significant impact on histological findings and there was no correlation between histology and outcome parameters such as pregnancy rates and fertilization, unless very severe histological aberrations ( $\geq$ SIGG 4) were present. These results are similar to those of another study of 86 men with non-obstructive azoospermia pregnancies for all histological groups except those with maturation arrest [55]. As could be expected, embryo quality as well as BMI of the male partner were found to be significantly associated with pregnancy after treatment. The limitations of this study are the retrospective nature of the study, that it was a single center analysis, and the limited number of patients. Additionally, information about delivery rates was limited [16] and was not evaluated here.

Our results can contribute to careful counseling offered to patients prior to TESE/ICSI treatment. However, the total number of analyzed patients was small and even smaller for each subgroup. This is also reflected in the results of the impact of BMI that was only found to significantly affect the outcomes of the first fresh cycle and not the following cycles.

\section{Conclusion}

In conclusion, embryo quality significantly influences the rate of successful pregnancies in patients undergoing TESE/ICSI. The success rate is further affected by the BMI of the male partner, with a lower BMI associated with a higher rate of conception after TESE/ ICSI treatment. The ongoing pregnancy rate decreased significantly after the second attempt at treatment, while BMI and age of the female partner and nicotine abuse by either partner did not affect the success rate of treatment. High-degree testicular atrophy (SIGG grade 4) is a poor prognostic factor for the success of TESE/ICSI. Considering these results, overweight men should be advised about weight optimization prior to therapy. A realistic ex- planation for the success rates of TESE/ICSI should take the histological results into consideration, even after sperm-positive biopsy.

\section{Author Contributions}

Each author contributed substantially to the drafting or critical revision of the manuscript, and approved the final version. J.R., A. G., S. R. conceived and designed the study. Data acquisition, data analysis and interpretation, and statistical analysis were performed by T.B., E.C., J.H., J.R., S.R., T.S. and A.G. The sperm count after testicular biopsy was carried out by J. D.

\section{Data Availability}

The data are available from the corresponding author on reasonable request.

\section{Ethical Approval and Informed Consent}

The study was conducted in accordance with the principles of the Declaration of Helsinki. The project was approved by the Ethics Committee of the Medical Faculty of Heidelberg University (\# S361-2008). All patients gave their informed consent and completed a clinical questionnaire.

\section{Conflict of Interest}

The authors declare that they have no conflict of interest.

\section{References}

[1] Practice Committee of the American Society for Reproductive Medicine. Electronic address: asrm@asrm.org. Management of nonobstructive azoospermia: a committee opinion. Fertil Steril 2018; 110: 1239-1245. doi:10.1016/j.fertnstert.2018.09.012

[2] Erdem E, Karacan M, Cebi Z et al. Results of intracytoplasmic sperm injection performed with sperm retrieved by microscopic testicular sperm extraction in azoospermic patients. Turk J Urol 2018; 44: 462-466. doi:10.5152/tud.2018.85282

[3] Vloeberghs V, Verheyen G, Haentjens P et al. How successful is TESE-ICSI in couples with non-obstructive azoospermia? Hum Reprod 2015; 30 : 1790-1796. doi:10.1093/humrep/dev139

[4] Ananthapur V, Avvari S, Veena K et al. Non-Robertsonian translocation T $(2 ; 11)$ is associated with infertility in an oligospermic man. Andrologia 2014; 46: 453-455. doi:10.1111/and. 12120

[5] Kate UV, Pokale YS, Jadhav AM et al. Chromosomal aberrations and polymorphic evaluation in males with primary infertility from Indian population. J Clin Diagn Res 2014; 8: SC01-SC06. doi:10.7860/JCDR/2014/ 8644.4933

[6] Tuttelmann F, Ruckert C, Ropke A. Disorders of spermatogenesis: Perspectives for novel genetic diagnostics after 20 years of unchanged routine. Med Genet 2018; 30: 12-20. doi:10.1007/s11825-018-0181-7

[7] Vogt PH, Edelmann A, Kirsch S et al. Human Y chromosome azoospermia factors (AZF) mapped to different subregions in Yq11. Hum Mol Genet 1996; 5: 933-943

[8] Colaco S, Modi D. Genetics of the human Y chromosome and its association with male infertility. Reprod Biol Endocrinol 2018; 16: 14. doi:10.1186/s12958-018-0330-5 
[9] Sigg C. [Classification of tubular testicular atrophies in the diagnosis of sterility. Significance of the so-called "bunte Atrophie"]. Schweiz Med Wochenschr 1979; 109: 1284-1293

[10] Yu Y, Xi Q, Wang R et al. Heterogenicity of testicular histopathology and tubules as a predictor of successful microdissection testicular sperm extraction in men with nonobstructive azoospermia. Medicine (Baltimore) 2018; 97: e10914. doi:10.1097/MD.0000000000010914

[11] Palermo G, Joris H, Devroey P et al. Pregnancies after intracytoplasmic injection of single spermatozoon into an oocyte. Lancet 1992; 340: 1718

[12] Donoso P, Tournaye H, Devroey P. Which is the best sperm retrieval technique for non-obstructive azoospermia? A systematic review. Hum Reprod Update 2007; 13: 539-549. doi:10.1093/humupd/dmm029

[13] Esteves SC, Agarwal A. Reproductive outcomes, including neonatal data, following sperm injection in men with obstructive and nonobstructive azoospermia: case series and systematic review. Clinics (Sao Paulo) 2013; 68 (Suppl. 1): 141-150

[14] Dabaja AA, Schlegel PN. Microdissection testicular sperm extraction: an update. Asian J Androl 2013; 15: 35-39. doi:10.1038/aja.2012.141

[15] Nicopoullos JD, Gilling-Smith C, Almeida PA et al. Use of surgical sperm retrieval in azoospermic men: a meta-analysis. Fertil Steril 2004; 82: 691-701. doi:10.1016/j.fertnstert.2004.02.116

[16] Osmanagaoglu K, Vernaeve V, Kolibianakis E et al. Cumulative delivery rates after ICSI treatment cycles with freshly retrieved testicular sperm: a 7-year follow-up study. Hum Reprod 2003; 18: 1836-1840

[17] Dafopoulos K, Griesinger G, Schultze-Mosgau A et al. Cumulative pregnancy rate after ICSI with cryopreserved testicular tissue in non-obstructive azoospermia. Reprod Biomed Online 2005; 10: 461-466

[18] Berger DS, Zapantis A, Merhi Z et al. Embryo quality but not pronuclear score is associated with clinical pregnancy following IVF. J Assist Reprod Genet 2014; 31: 279-283. doi:10.1007/s10815-013-0162-3

[19] Gardner DK, Lane M, Stevens ] et al. Blastocyst score affects implantation and pregnancy outcome: towards a single blastocyst transfer. Fertil Steril 2000; 73: 1155-1158

[20] Racowsky C, Stern JE, Gibbons WE et al. National collection of embryo morphology data into Society for Assisted Reproductive Technology Clinic Outcomes Reporting System: associations among day 3 cell number, fragmentation and blastomere asymmetry, and live birth rate. Fertil Steril 2011; 95: 1985-1989. doi:10.1016/j.fertnstert.2011.02.009

[21] Vernon M, Stern JE, Ball GD et al. Utility of the national embryo morphology data collection by the Society for Assisted Reproductive Technologies (SART): correlation between day-3 morphology grade and live-birth outcome. Fertil Steril 2011; 95: 2761-2763. doi:10.1016/j.fertnstert. 2011.02.008

[22] Ramlau-Hansen CH, Thulstrup AM, Nohr EA et al. Subfecundity in overweight and obese couples. Hum Reprod 2007; 22: 1634-1637. doi:10.1093/humrep/dem035

[23] Mushtaq R, Pundir J, Achilli C et al. Effect of male body mass index on assisted reproduction treatment outcome: an updated systematic review and meta-analysis. Reprod Biomed Online 2018; 36: 459-471. doi:10.1016/j.rbmo.2018.01.002

[24] Ramlau-Hansen CH, Thulstrup AM, Aggerholm AS et al. Is smoking a risk factor for decreased semen quality? A cross-sectional analysis. Hum Reprod 2007; 22: 188-196. doi:10.1093/humrep/del364

[25] Goldstein M, Schlegel PN. Testis Biopsy. In: Goldstein M, Schlegel PN, eds. Surgical and medical Management of male Infertility. UK: Cambridge University Press; 2013: 62-66. ISBN 9780521881098

[26] von Wolff M, Kollmann Z, Fluck CE et al. Gonadotrophin stimulation for in vitro fertilization significantly alters the hormone milieu in follicular fluid: a comparative study between natural cycle IVF and conventional IVF. Hum Reprod 2014; 29: 1049-1057. doi:10.1093/humrep/deu044
[27] Veek LL. Preembryo Grading and Degree of cytoplasmic Fragmentation. In: Veek LL, ed. An Atlas of human Gametes and Conceptuses: an illustrated Reference for assisted reproductive Technology. CRC Press; 1999: 46-51

[28] Gardner DK, Schoolcraft WB. In vitro Culture of human Blastocyst. In: Jansen R, Mortimer D, eds. Towards reproductive Certainty: Infertility and Genetics Beyond. Carnforth: Parthenon Press; 1999: 377-388

[29] Ziebe S, Petersen K, Lindenberg S et al. Embryo morphology or cleavage stage: how to select the best embryos for transfer after in-vitro fertilization. Hum Reprod 1997; 12: 1545-1549

[30] Zhu J, Lian Y, Li M et al. Does IVF cleavage stage embryo quality affect pregnancy complications and neonatal outcomes in singleton gestations after double embryo transfers? J Assist Reprod Genet 2014; 31: 16351641. doi:10.1007/s10815-014-0351-8

[31] Ma J, Wu L, Zhou Y et al. Association between BMI and semen quality: an observational study of 3966 sperm donors. Hum Reprod 2019; 34: 155162. doi:10.1093/humrep/dey328

[32] Sallmen M, Sandler DP, Hoppin JA et al. Reduced fertility among overweight and obese men. Epidemiology 2006; 17: 520-523. doi:10.1097/01.ede.0000229953.76862.e5

[33] Sharma R, Harlev A, Agarwal A et al. Cigarette Smoking and Semen Quality: A New Meta-analysis Examining the Effect of the 2010 World Health Organization Laboratory Methods for the Examination of Human Semen. Eur Urol 2016; 70: 635-645. doi:10.1016/j.eururo.2016.04.010

[34] Engin-Ustun Y, Yilmaz N, Akgun N et al. Body Mass Index Effects Kruger's Criteria in Infertile Men. Int J Fertil Steril 2018; 11: 258-262. doi:10.22074/ijfs.2018.4888

[35] Shukla KK, Chambial S, Dwivedi S et al. Recent scenario of obesity and male fertility. Andrology 2014; 2: 809-818. doi:10.1111/andr.270

[36] Hakonsen LB, Thulstrup AM, Aggerholm AS et al. Does weight loss improve semen quality and reproductive hormones? Results from a cohort of severely obese men. Reprod Health 2011; 8: 24. doi:10.1186/17424755-8-24

[37] Ramasamy R, Bryson C, Reifsnyder JE et al. Overweight men with nonobstructive azoospermia have worse pregnancy outcomes after microdissection testicular sperm extraction. Fertil Steril 2013; 99: 372-376. doi:10.1016/j.fertnstert.2012.10.025

[38] Toth B, Baston-Büst DM, Behre HM et al. Diagnosis and Treatment Before Assisted Reproductive Treatments. Guideline of the DGGG, OEGGG and SGGG (S2k Level, AWMF Register Number 015-085, February 2019) Part 2, Hemostaseology, Andrology, Genetics and History of Malignant Disease. Geburtsh Frauenheilk 2019; 79: 1293-1308

[39] Paasch U, Grunewald S, Kratzsch J et al. Obesity and age affect male fertility potential. Fertil Steril 2010; 94: 2898-2901. doi:10.1016/ j.fertnstert.2010.06.047

[40] Garolla A, Torino M, Miola P et al. Twenty-four-hour monitoring of scrotal temperature in obese men and men with a varicocele as a mirror of spermatogenic function. Hum Reprod 2015; 30: 1006-1013. doi:10.1093/ humrep/dev057

[41] Fedorcsak P, Dale PO, Storeng R et al. Impact of overweight and underweight on assisted reproduction treatment. Hum Reprod 2004; 19 : 2523-2528. doi:10.1093/humrep/deh485

[42] van der Steeg JW, Steures P, Eijkemans MJ et al. Obesity affects spontaneous pregnancy chances in subfertile, ovulatory women. Hum Reprod 2008; 23: 324-328. doi:10.1093/humrep/dem371

[43] Rehman R, Irfan T, Jawed $S$ et al. Embryo quality in intracytoplasmic sperm injection: A quasi experimental design in Pakistan. J Pak Med Assoc 2018; 68: 1451-1455

[44] Abdel Raheem A, Rushwan N, Garaffa G et al. Factors influencing intracytoplasmic sperm injection (ICSI) outcome in men with azoospermia. BJU Int 2013; 112: 258-264. doi:10.1111/j.1464-410X.2012.11714.x 
[45] Elhanbly S, El-Saied MA, Fawzy M et al. Relationship of paternal age with outcome of percutaneous epididymal sperm aspiration-intracytoplasmic sperm injection, in cases of congenital bilateral absence of the vas deferens. Fertil Steril 2015; 104: 602-606. doi:10.1016/j.fertnstert.2015.06. 020

[46] Stolwijk AM, Wetzels AM, Braat DD. Cumulative probability of achieving an ongoing pregnancy after in-vitro fertilization and intracytoplasmic sperm injection according to a woman's age, subfertility diagnosis and primary or secondary subfertility. Hum Reprod 2000; 15: 203-209

[47] Lintsen AM, Eijkemans MJ, Hunault CC et al. Predicting ongoing pregnancy chances after IVF and ICSI: a national prospective study. Hum Reprod 2007; 22: 2455-2462. doi:10.1093/humrep/dem183

[48] Durairajanayagam D. Lifestyle causes of male infertility. Arab J Urol 2018; 16: 10-20. doi:10.1016/j.aju.2017.12.004

[49] Li Y, Lin H, Li Y et al. Association between socio-psycho-behavioral factors and male semen quality: systematic review and meta-analyses. Fertil Steril 2011; 95: 116-123. doi:10.1016/j.fertnstert.2010.06.031

[50] Kovac JR, Khanna A, Lipshultz LI. The effects of cigarette smoking on male fertility. Postgrad Med 2015; 127: 338-341. doi:10.1080/ 00325481.2015 .1015928
[51] Heger A, Sator M, Walch K et al. Smoking Decreases Endometrial Thickness in IVF/ICSI Patients. Geburtsh Frauenheilk 2018; 78: 78-82. doi:10.1055/s-0043-123762

[52] Gruber I, Just A, Birner M et al. Effect of a woman's smoking status on oocyte, zygote, and day 3 pre-embryo quality in in vitro fertilization and embryo transfer program. Fertil Steril 2008; 90: 1249-1252. doi:10.1016/j.fertnstert.2007.06.108

[53] Taitson PF, Mourthe AF, Radaelli MRM. Testicular sperm extraction in men with Sertoli cell-only testicular histology - 1680 cases. JBRA Assist Reprod 2019; 23: 246-249. doi:10.5935/1518-0557.20190023

[54] Aydin T, Sofikerim M, Yucel B et al. Effects of testicular histopathology on sperm retrieval rates and ICSI results in non-obstructive azoospermia. J Obstet Gynaecol 2015; 35: 829-831. doi:10.3109/01443615.2015. 1009879

[55] Friedler S, Raziel A, Schachter M et al. Outcome of first and repeated testicular sperm extraction and ICSI in patients with non-obstructive azoospermia. Hum Reprod 2002; 17: 2356-2361 